\title{
KARAKTERISTIK POHON UNTUK TIDUR MONYET EKOR PANJANG (Macaca fascicularis) DI KAWASAN YOUTH CAMP TAMAN HUTAN RAYA WAN ABDUL RACHMAN LAMPUNG
}

\section{TREE CHARACTERISTICS FOR SLEEPING OF THE LONG TAILED MACAQUES (Macaca fascicularis) IN YOUTH CAMP AREA OF GREAT FOREST PARK OF WAN ABDUL RACHMAN LAMPUNG}

\author{
Aji Setiawan ${ }^{1}$, M. Kanedi ${ }^{1}$, Elly L. Rustiati ${ }^{1}$, Ronald H.P. Panjaitan ${ }^{2}$ \\ ${ }^{1}$ Jurusan Biologi FMIPA Universitas Lampung \\ ${ }^{2}$ UPTD Taman Hutan Raya Wan Abdul Rachman Provinsi Lampung \\ e-mail : setiawan_aji11@yahoo.co.id \\ Jurusan Biologi FMIPA Universitas Lampung \\ Jl. Prof.Dr. Soemantri Brojonegoro No. 1, Bandar Lampung, Lampung, Indonesia, 35145
}

\begin{abstract}
Abstrak
Monyet ekor panjang (Macaca fascicularis) adalah primata yang mudah beradaptasi dengan aktivitas manusia. Jenis monyet ini mudah dijumpai di kawasan hutan yang dekat dengan kawasan pemukiman, perladangan, dan perkebunan, contohnya adalah area Youth Camp di Taman Hutan Raya Wan Abdul Rachman di Kabupaten Pesawaran, Lampung. Penelitian ini dilaksanakan menggunakan Metode Observasi dari bulan Agustus sampai September 2012 di areal Youth Camp Taman Hutan Raya Wan Abdul Rachman Lampung. Parameter yang diamati adalah saat monyet istirahat (immobile), yaitu diam, berdiri, duduk, tidur, serta posisi saat mencari lokasi untuk tidur pada suatu pohon sehingga dapat diketahui jenis pohonnya. Data yang terkumpul diinterpretasikan secara deskriptif. Terdapat enam jenis pohon yang digunakan untuk tidur yaitu bambu (Bambusa sp.), dahu (Dracontomelon dao Merr. Et Rolfe.), ki hujan (Samanea saman (Jacq.) Merr.), pulai (Alstonia pneumatophora Back. Ex don Berger.), dadap (Erythrina variegate L.), benda (Artocarpus elasticus Reinw. ex Blume). Pohon untuk tidur monyet ekor panjang berkarakteristik tinggi dan memiliki tajuk yang luas, serta dekat dengan sumber air.
\end{abstract}

Kata kunci: Tahura Wan Abdul Rachman, Macaca fascicularis, pohon tidur.

\begin{abstract}
Long tailed macaques (Macaca fascicularis) is an adaptive primate to the human being activity and hence the monkey is easy to meet in forest area closed to settlement area, farm, and plantation, for example Youth Camp Area in the Great Forest Park of Wan Abdul Rachman, Pesawaran Regency, Province Of Lampung. The study was carried out by using the Observation Method from August to September 2012 in Youth Camp area of the Great Forest Park Area of Wan Abdul Rachman. Some parameters observed in the study include the take rest periode, sitting, sleeping, and also arboreal movement to get proper place for sleeping at one particular tree. All of the collected data were interpretated descriptively. There were six tree species used by the long tailed monkey for sleeping such as bamboo (Bambusa sp.), dahu (Dracontomelon dao Merr. Et Rolfe.), ki hujan (Samanea saman (Jacq.) Merr.), pulai (Alstonia pneumatophora Back. Ex of Don Berger.), dadap (Erythrina variegate L.), benda (Artocarpus elasticus Reinw. ex Blume). Generally the trees used for sleeping are high with wide and dense crown, and also close to source of water.
\end{abstract}

Key words: Wan Abdul Rachman Great Forest Park, Long tailed macaques, tree sleep.

\section{PENDAHULUAN}

Menurut Napier and Napier (1985), Macaca merupakan genus yang mudah beradaptasi dengan berbagai lingkungan pada daerah iklim yang berbeda. Sebagai contoh, monyet dapat tinggal di hutan primer, sekunder, pesisir pantai, bakau, ra- wa, dan sungai dengan ketinggian mulai dari permukaan laut sampai $2000 \mathrm{~m}$ di atas permukaan laut (Lucas et.al., 1998).

Perilaku harian monyet di habitat alami terdiri atas $35 \%$ untuk makan, $20 \%$ penjelajahan, $34 \%$ 
istirahat, $12 \%$ untuk grooming, dan kurang dari 0,5\% untuk aktivitas lainnya (Santosa, 1996).

Monyet merupakan primata diurnal, dan pada umumnya akan beristirahat pada tengah hari ataupun pada tengah malam. Monyet tidur pada malam hari di atas pohon, diantaranya ada yang membuat sarang dan ada pula yang tidak. Beberapa individu tidur di atas pohon yang tinggi dan tidak ditumbuhi liana. Selain itu, keadaan pohon tempat tidur berhubungan dengan aktivitas makan dan pertahanan hidup terhadap musuh alami berupa predator, parasit, dan penyakit (Sari, 2009). Penelitian ini bertujuan untuk mengetahui jenis pohon dan karakteristik pohon yang digunakan oleh monyet sebagai tempat tidur.

\section{BAHAN dan METODE}

Penelitian ini dilaksanakan dari bulan Agustus sampai dengan September 2012 di hutan Damar kaca dan Sungkai area Youth Camp Tahura Wan Abdul Rachman Provinsi Lampung.

Metode yang digunakan dalam penelitian inii berupa observasi, dengan cara mengamati langsung perilaku saat spesies ini tidur dan peneliti tidak terlibat dalam kegiatan monyet. Pengamatan dilakukan pada satu kelompok monyet menggunakan teropong binokuler. Pengamatan dilakukan dua kali setiap hari yaitu saat monyet memulai aktivitasnya pada jam 06.00 dan saat monyet memulai waktu tidurnya pada jam 17.30 hingga tidak ditemukan aktivitas lagi pada kelompok monyet tersebut. Pengamatan ini dilakukan selama 3 (tiga) hari berturutturut dan dilakukan pengulangan 3 (tiga).

Dua parameter yang menjadi acuan penelitian adalah parameter biologis dan lingkungan. Parameter biologis yang diamati adalah saat istirahat, yaitu berdiri, duduk, tidur, serta posisi saat spesies ini mencari lokasi untuk tidur pada suatu pohon. Selain itu juga dilakukan pengamatan karakteristik pohon yang meliputi ada tidaknya buah, ada tidaknya liana, hubungan liana antar pohon serta bagian pohon yang digunakan oleh monyet, jenis percabangan, diameter pohon, luas tajuk, dan tinggi total.Parameter lingkungan yang diamati meliputi ketinggian lokasi, topografi, jarak dengan sumber air dan jalan setapak, cua$\mathrm{ca}$, serta frekuensi pemakaian pohon untuk tidur.

\section{HASIL dan PEMBAHASAN}

Selain data karakteristik biologis jenis pohon tidur (Tabel 1), dilakukan juga pencatatan data tentang karakteristik lingkungan jenis pohon tidur sebagai bahan rujukan untuk mengetahui karakteristik lingkungan seperti ketinggian lokasi, topografi atau kemiringan lokasi, jarak dengan sumber air dan jalan setapak, serta frekuensi pemakaian pohon tidur tersebut oleh monyet ekor panjang (Tabel 2).

Tabel 1. Data karakteristik biologis jenis pohon untuk tidur monyet ekor panjang

\begin{tabular}{|l|l|c|c|c|c|c|}
\hline No. & \multicolumn{1}{|c|}{ NP } & $\begin{array}{c}\text { TT } \\
(\mathrm{m})\end{array}$ & $\begin{array}{c}\text { TBC } \\
(\mathrm{m})\end{array}$ & $\begin{array}{c}\text { DB } \\
(\mathrm{cm})\end{array}$ & $\begin{array}{c}\text { LK } \\
\left(\mathrm{m}^{2}\right)\end{array}$ & JP \\
\hline 1. & Bambu 1 & 14 & - & - & 154 & $\mathrm{M}$ \\
& Bambu 2 & 11 & - & - & 113 & $\mathrm{M}$ \\
\hline 2. & Dahu 1 & 31 & 25 & 310 & 177 & $\mathrm{D}$ \\
& Dahu 2 & 22 & 17 & 220 & 113 & $\mathrm{D}$ \\
& Dahu 3 & 24 & 18 & 220 & 227 & $\mathrm{D}$ \\
& Dahu 4 & 33 & 26 & 230 & 314 & $\mathrm{D}$ \\
& Dahu 5 & 23 & 16 & 215 & 177 & $\mathrm{D}$ \\
\hline 3. & Ki hujan & 18 & 9 & 110 & 95 & $\mathrm{D}$ \\
\hline 4. & Dadap & 19 & 11 & 242 & 113 & $\mathrm{D}$ \\
\hline 5. & Pulai & 21 & 13 & 110 & 113 & $\mathrm{D}$ \\
\hline 6. & Benda & 20 & 14 & 125 & 113 & $\mathrm{D}$ \\
\hline
\end{tabular}

Keterangan : NP) nama pohon; TT) tinggi total; TBC) tinggi bebas cabang; DB) diameter batang; LK) lebar kanopi; M) monopodial; D) dikotom.

Tabel 2. Data karakteristik lingkungan jenis pohon tidur monyet ekor panjang (Macaca fascicularis)

\begin{tabular}{|c|c|c|c|c|c|}
\hline \multirow{2}{*}{ No. } & \multirow{2}{*}{ NP } & \multirow{2}{*}{$\mathrm{T}\left({ }^{\circ}\right)$} & \multicolumn{2}{|c|}{ Jarak (m) } & \multirow{2}{*}{ FP } \\
\hline & & & SA & JS & \\
\hline \multirow[t]{2}{*}{1.} & Bambu 1 & $4^{\circ}$ & 50 & 120 & 2 \\
\hline & Bambu 2 & $4^{\circ}$ & 2 & 120 & 2 \\
\hline \multirow[t]{5}{*}{2.} & Dahu 1 & $60^{\circ}$ & 7 & 120 & 1 \\
\hline & Dahu 2 & $70^{\circ}$ & 10 & 120 & 2 \\
\hline & Dahu 3 & $50^{\circ}$ & 15 & 100 & 2 \\
\hline & Dahu 4 & $30^{\circ}$ & 4 & 100 & 2 \\
\hline & Dahu 5 & $80^{\circ}$ & 1 & 100 & 3 \\
\hline 3. & Ki hujan & $5^{\circ}$ & 50 & 110 & 9 \\
\hline 4. & Dadap & $25^{\circ}$ & 7 & 100 & 2 \\
\hline 5. & Pulai & $30^{\circ}$ & 11 & 100 & 3 \\
\hline 6. & Benda & $30^{\circ}$ & 9 & 100 & 2 \\
\hline
\end{tabular}

Keterangan : T) topografi; SA) sumber air; JS) jalan setapak; FP) frekuensi pemakaian

Monyet ekor panjang tidak memiliki ketergantungan dalam memilih pohon untuk tidur dan tidak menunjukkan perilaku bersarang. Hal ini dibuktikan dengan tidak ditemukannya monyet yang tidur di satu pohon yang sama dalam dua hari berturut-turut. Untuk tidur, monyet biasanya memilih pohon yang tinggi. Alasan pemilihan jenis pohon yang tinggi yaitu untuk menghindari predator dan gangguan yang muncul termasuk aktivitas manusia. Hasil penelitian juga menun- 
jukkan bahwa monyet ekor panjang juga memilih jenis pohon yang memiliki sumber persyaratan hidup seperti adanya naungan dan sumber air.

Pohon dahu merupakan salah satu jenis pohon sumber pakan monyet yaitu buah dan pucuk daun. Selain itu, pohon dahu juga memberikan naungan yang baik karena memiliki tinggi yang dominan dan luas tutupan tajuk yang lebih luas dan rapat dibanding dengan pohon lain yang berada di kawasan tersebut. Banyaknya tumbuhan liana di sekitar pohon tersebut dan bentuk topografi tebing batu dengan kemiringan rata-rata di atas $60^{\circ}$ juga memberikan perlindungan bagi monyet ekor panjang dari ancaman predator dan memudahkan pergerakan dalam kegiatan kesehariannya. Salah satu faktor habitat yang penting adalah sumber air. Kebanyakan pohon dahu yang digunakan sebagai pohon utuk tidur berada di sepanjang aliran sungai. Hal ini semakin melengkapi ketersediaan syarat hidup yang dibutuhkan oleh monyet sehingga monyet cenderung memilih pohon ini. Kadang-kadang, pohon yang digunakan untuk tidur monyet ekor panjang tidak sekaligus sebagai sumber pakan. Hal ini diduga untuk menghindari adanya gangguan dari spesies lain yang akan memanfaatkan pohon sebagai sumber pakan.

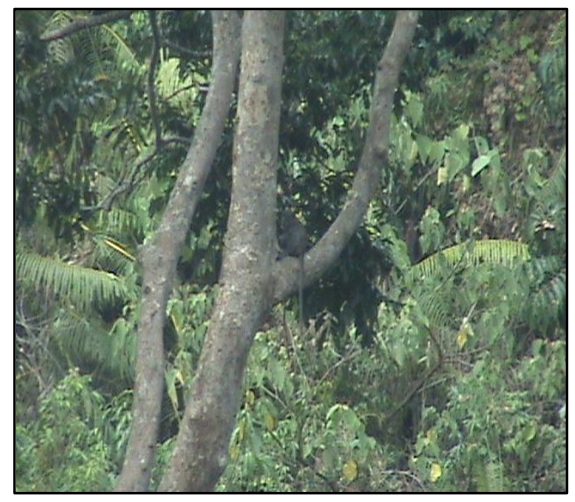

Gambar 1. Monyet ekor panjang tidur di pohon dahu.

Pohon ki hujan merupakan pohon yang memiliki syarat hidup bagi monyet ekor panjang seperti naungan dan dekat dengan sumber air. Selain itu, bentuk percabangan pohon ki hujan yang dikotom membentuk suatu tajuk yang rapat dan terlindung sehingga memberikan naungan dan tempat berlindung yang aman bagi monyet ekor panjang. Letak pohon ki hujan yang berada di puncak tebing dan ditutupi oleh liana juga memberikan keamanan ekstra dari ancaman predator dan gangguan manusia. Ketiadaan buah yang dapat dimanfaatkan sebagai sumber pakan juga meminimalisir terjadinya persaingan dalam perebutan makanan. Oleh karena itu, monyet paling menyukai pohon ini sebagai tempat tidurnya yang dibuktikan dengan tingginya frekuensi pemakaian pohon ki hujan sebagai pohon tidur.

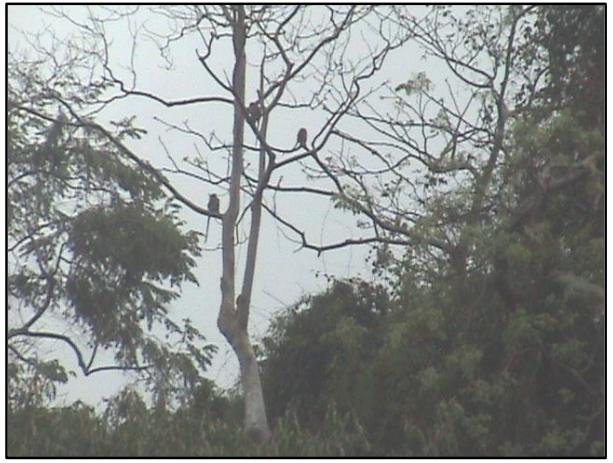

Gambar 2. Monyet ekor panjang tidur di pohon ki hujan.

Pohon dadap, benda, dan pulai adalah jenis lain untuk tidur monyet. Letak pohon ini berada dalam area yang berdekatan, dan berada di sepanjang aliran sungai. Ketiga jenis pohon tersebut memiliki tinggi berkisar antara 17-20 m dan luas tajuk berkisar $38,5-113 \mathrm{~m}^{2}$. Selain itu, keberadaan liana dan vegetasi lain yang tumbuh dengan subur dan lebat di sekitar pohon ini menyebabkan keberadaan ketiga pohon ini seolah-olah tersembunyi. Letak ketiga pohon tersebut yang berada di area tebing dengan kemiringan lokasi mencapai $12-50^{\circ}$ dengan komposisi dominan berupa liana memberikan keamanan dari predator dan pengganggu lainnya, selain itu lokasi pohon yang berada dekat dengan dengan sumber air juga menyebabkan monyet cenderung memilih pohon ini sebagai pohon untuk tidur.

Jenis pohon lain yang digunakan sebagai pohon untuk tidur monyet ekor panjang adalah bambu. Vegetasi bambu disukai oleh monyet karena tajuk bambu yang rapat sehingga cocok untuk tempat berlindung dan tempat beristirahat. Untuk menjamin kelangsungan berbagai kegiatan dan juga untuk mempertahankan kehidupannya maka kehadiran pelindung sangat dibutuhkan (Alikodra, 2002). Selain itu, letaknya yang sangat dekat dengan sumber air yaitu sungai kecil dan memiliki jarak yang cukup jauh dari perkebunan dan jalan yang sering dilalui oleh masyarakat juga memberikan kenyamanan dan keamanan bagi monyet ekor panjang dalam kegiatan istirahatnya.

Monyet ekor panjang selalu memilih jenis pohon yang berbeda yang akan digunakan sebagai pohon tidur dan tergantung pada ketersediaan makanan, kondisi cuaca, dan keberadaan gangguan. Ketersediaan makanan erat hubungannya dengan daerah jelajah yang ditempuh oleh kawanan monyet. Monyet ekor panjang selalu berpin- 
dah lokasi dalam mencari makan tergantung pada ketersediaan makanan. Apabila jumlah pakan yang tersedia di suatu area berkurang, maka monyet tersebut akan berpindah mencari daerah yang memiliki jumlah makanan yang mencukupi. Sementara itu, keadaan cuaca juga berpengaruh dalam pemilihan pohon tidur. Saat cuaca normal dan tidak turun hujan, monyet ekor panjang akan memilih jenis pohon yang tinggi. Namun, apabila cuaca dalam keadaan hujan, kawanan monyet cenderung akan memilih pohon yang memiliki tutupan tajuk yang luas, rimbun, dan ternaungi sehingga terlindung dari guyuran hujan.

Apabila terdapat gangguan yang dapat mengancam keberadaannya, kawanan monyet akan segera berpindah menuju pohon yang lebih aman dan biasanya terus berpindah sampai menemukan pohon yang dirasa cukup aman dari gangguan predator, yaitu pohon yang lebih tinggi dan rimbun. Jenis gangguan yang biasa adalah keberadaan predator yaitu elang. Selain itu, jenis gangguan lain yang biasanya timbul berasal dari anjing peliharaan masyarakat dan dari manusia sendiri yang melintas di sekitar pohon untuk tidur monyet.

Selain faktor ketersediaan makanan, keamanan, dan cuaca yang mempengaruhi pola pemilihan jenis pohon untuk tidur adalah pohon yang berada di sekitar sumber air, karena sumber air merupakan salah satu faktor penunjang kehidupan, yaitu untuk kebutuhan minum. Selain itu, kondisi sekitar sumber air, dalam hal ini sungai, terdapat pepohonan tinggi yang potensial untuki tidur dan ditumbuhi liana yang cukup rapat dan mendominasi kawasan tersebut sehingga secara tidak langsung menyediakan tempat berlindung yang aman dan terhindar dari bahaya musuh maupun predator.

\section{KESIMPULAN}

Monyet ekor panjang cenderung menyukai jenis pohon untuk tidur yang berkarakteristik tinggi, memiliki tajuk yang luas dan terlindung, serta berada dekat dengan sumber air.

\section{DAFTAR PUSTAKA}

Alikodra,H.S. 1990. Studi Ekologi Bekantan (Nasalis larvatus) di Hutan Lindung Bukit Soeharto Kalimantan Timur. Laporan penelitian kerjasama Depdikbud dan JICA.

Chalmers, N. 1979. Social Behaviour in Primates. Contemporary Biology. Edward Arnold. London.
Djuwantoko, R.N. Utami dan Wiyono. 2008. Perilaku Agresif Monyet Ekor Panjang (Macaca fascicularis) Terhadap Wisatawan di Hutan Wisata Alam Kaliurang Yogyakarta. Jurnal Penelitian. Fakultas Kehutanan. Universitas Gadjah Mada.

Farida, H.. 2008. Aktivitas Makan Monyet Ekor Panjang (Macaca fascicularis) di Bumi Perkemahan Pramuka Cibubur. Jakarta:. Skripsi. Departemen Biologi Fakultas Matematika dan IImu Pengetahuan Alam Institut Pertanian Bogor.

Kemp, N. J. And Burnett, J. B.. 2003. Final Report: A Biodiversity Risk Asessment and Recomendations For Risk Management of Long Tailed Macaques (Macaca fascicularis) in New Guinea December 2003. Washington, DC: Indo-Pacific Conservation Alliance.

Leger, D.W. 1992. Biological Foundations of Behaviour: An integrative Approach, Harpen Collins Publisher. New York.

Lucas P.W., and R.T., Corlett. 1998. Seed dispersal by long-tailed macaque. American Journal of Primatology 45 (1): 19-44.

Napier, J. R. and P. H. Napier. 1985. The Natural History of the Primates. The MIT Press, Cambridge, Massachusetts.

Priatna ,B.. 2003. Tingkah Laku Seksual Monyet Ekor Panjang (Macaca fascicularis) di Pulau Tinjil Kabupaten Pandeglang. Program Studi Teknologi Produksi Ternak Fakultas Pertanian IPB. Bogor.

Sari, D.D. 2009. Profil Darah Monyet Ekor Panjang (Macaca fascicularis) yang diberi pakan berenergi tinggi pada periode obesitas empat bulan kedua. Departemen IImu Produksi dan Teknologi Peternakan, Fakultas Peternakan, IPB. Bogor.

Setiawan, A.. 2000. Nilai Ekonomi Taman Nasional Wan Abdul Rachman Propinsi Lampung. Program Pascasarjana IPB. Bogor

Setyawan, K. 1996. Interaksi Antara Monyet Ekor Panjang(Macaca fascicularis) dan Lutung (Prebitys cristata) di Taman Nasional Baluran. Malang: FMIPA Universitas Brawijaya.

Sinaga, S., Pranoto U. M., Surono H., Archaitra N. A.. 2011. Pemanfaatan Habitat Oleh Monyet Ekor Panjang di Kampus IPB Darmaga. Bogor: Departemen Konservasi Sumberdaya Hutan dan Ekowisata Fakultas Kehutanan IPB.

Supriatna, J. dan Hendras W. E. 2000. Panduan Lapangan Primata Indonesia. Jakarta : Yayasan Obor Indonesia. 